\title{
ANALISIS DAN FORMULASI STRATEGI KETERSEDIAAN AIR BERSIH DI LOKASI TRANSMIGRASI (STUDI KASUS: KACAMATAN LASALIMU SELATAN KABUPATEN BUTON)
}

\section{Analysis and Strategy Formulation for Clean Water Availability in Transmigration Area (A Case Study: The Sub-District of South Lasalimu, The District of Buton)}

\author{
Novita Estika ${ }^{\mathrm{a}}$, Suprihatin ${ }^{\mathrm{b}}$, M. Yani ${ }^{\mathrm{b}}$ \\ ${ }^{a}$ Program Studi Pengelolaan dan Sumberdaya Alam dan Lingkungan, Sekolah Pasca Sarjana, Institut Pertanian \\ Bogor, Kampus IPB Darmaga, Bogor 16680 —novita.estika@yahoo.co.id. \\ ${ }^{b}$ Departemen Teknologi Industri Pertanian, Fakultas Teknologi Pertanian, Institut Pertanian Bogor, Kampus IPB \\ Darmaga, Bogor 16680
}

\begin{abstract}
The clean water is not always a big city's issue. A sub-district of South Lasalimu is an example of how a clean water problem exists due to natural factor. This research work aims to assess the availability of water clean sources in a transmigration area. The based on this assessment a strategy for clean water management in the area is formulated. This research used methods of water quality analysis, Guttman scale, requirement analysis, water quantity analysis, and SWOT analysis. The research identified that water resources available in the area consist of well water, water river, and rainwater. The daily need of clean water per person was is identified as 59 Liter, so all local residents in the area require approx. 15,656 $\mathrm{m}^{3} /$ year. It is necessarily important to manage water resources in order to fulfill the need of clean water. An alternative for clean water management is by utilizing rain water to secure the clean water supply. With the rainfall of about 3,681 $\mathrm{mm} / y$ ear, there would be 18,405 $\mathrm{m}^{3} /$ year of clean water can be collected from the rain. There are several steps to utilize the rain water through retention basin, filtration, and gravity distribution. This research also delivers an alternative strategy for an effective water resources management which used an opportunity to minimize weakness (W-O strategy), with primary priority to ask for government support in their capacity and capability (authority) to manage water resources.
\end{abstract}

Keywords: Water resource management strategy, natural contaminant, SWOT analysis, transmigration area

(Diterima: 24-11-2016; Disetujui: 28-03-2017)

\section{Pendahuluan}

Persoalan air bersih tidak hanya terjadi di kota besar. Permasalahan ini terjadi juga di daerah pedesaan seperti yang terjadi di Kabupaten Buton Provinsi Sulawesi Tenggara. Salah satu lokasi transmigrasi di Kecamatan Lasalimu Selatan pelayanan terhadap kebutuhan air bersih belum terpenuhi secara menyeluruh dan terpadu. Beberapa daerah transmigrasi di Indonesia, seperti Kalimantan dan Sumatera juga ternyata menghadapi masalah yang sama (Herlambang dan Said, 2005). Padahal salah satu indikator target pencapaian MDGs 2015 adalah air bersih yakni "mengurangi setengah dari jumlah penduduk yang tidak memiliki akses air minum yang sehat" (Unicef, 2012).

Menurut Herlambang (2006), potensi ketersediaan air di Indonesia pada tahun 2020 diperkirakan tinggal $1200 \mathrm{~m}^{3} / \mathrm{kapita} / \mathrm{tahun}$ dan hanya $35 \%$ yang layak dikelola, sehingga potensinya tinggal 400 $\mathrm{m}^{3} / \mathrm{kapita} /$ tahun. Suatu angka yang mengkhawatirkan dan perlu diwaspadai agar tidak terjadi defisit air. Beberapa daerah mengalami kekritisan air, khusus saat musim kemarau, pembangunan $\mathrm{PAH}$ (Penampungan Air Hujan) dapat dijadikan alternatif (Muliranti dan Hadi, 2013), seperti di daerah Bangko
Bagansiapiapi juga menggunakan air hujan sebagai sumber air minum (Anuar et al., 2015).

Hal yang sama dirasakan pula oleh warga di ibukota Kecamatan Glagah Lamongan, dimana warga mengalami kesulitan mendapatkan air bersih yang layak untuk memenuhi kebutuhan sehari-hari, terlebih pada saat musim kemarau, air sungai dan sumur yang digunakan ternyata juga kurang sehat untuk dikonsumsi warga (Lubis dan Affandy, 2014). Di Desa Kedungkarang Demak, juga mengalami krisis air akibat perubahan iklim yang berpengaruh pada sumberdaya air yang ada menyebabkan warga sulit mengakses air bersih dalam memenuhi kebutuhan domestiknya (Amalia dan Sugiri, 2014). Krisis air juga dapat terjadi akibat adanya pencemaran air (Sudiran et al., 2016; Setyaningsih, 2010).

Berdasarkan uraian di atas, maka ketersediaan dan kualitas air bersih sangat diperlukan dan harus sesuai karakteristik air guna mencapai standar kualitas air dengan mengacu pada Peraturan Pemerintah No. 82 Tahun 2001 tentang Pengelolaan Kualitas Air dan Pengendalian Pencemaran Air, sedangkan untuk penyediaan air bersih yang layak air minum harus memenuhi syarat-syarat sesuai dengan Permenkes RI. No. 416/MENKES/Per/IX/1990. Untuk merealisasikan hal tersebut maka dilakukan analisis 
ketersediaan sumber air bersih, baik itu kuantitas maupun kualitas air.

Daerah transmigrasi Kecamatan Lasalimu Selatan menghadapi kesulitan air bersih, terutama di musim kemarau dalam mengakses pasokan air bersih dan berkualitas. Hal ini disebabkan pada saat musim kemarau sumur galian penduduk tersebut mengalami kekeringan. Daerah ini juga memiliki kondisi letak geografis yang berada diperbukitan sehingga pasokan air bersih sangat sulit untuk diakses oleh masyarakat setempat karena faktor alam yang berbeda dari daerah di sekitarnya, yang mengakibatkan menurunnya kualitas air sumur dan berkurangnya kuantitas air bersih dalam memenuhi kebutuhan masyarakat.

Penelitian ini bertujuan untuk: (1) Mengidentifikasi potensi dan persebaran ketersediaan sumberdaya air; (2) Menghitung kebutuhan air bersih untuk masyarakat; (3) Menentukan pengelolaan sumberdaya air yang tepat sehingga kebutuhan air bersih dapat dikelola secara optimal; (4) Menentukan proses pengolahan air baku yang efisien agar air dapat layak dikonsumsi (5) Merancang strategi pengelolaan sumberdaya air yang efektif.

\section{Metode}

\subsection{Tahapan penelitian}

Penelitian ini dilakukan dalam beberapa tahapan, sebagai berikut (Gambar 1):

\section{a. Survei Lokasi}

Peneliti langsung meninjau ke lokasi penelitian yaitu Desa Harapan Jaya, Kecamatan Lasalimu Selatan untuk mengetahui keadaan/ kondisi lokasi penelitian dengan cara mengumpulkan data-data sekunder dari sampel yang akan diteliti.

\section{b. Identifikasi Ketersediaan Air}

Metode analisis data yang digunakan yaitu skala Guttman. Dalam melakukan analisis diberikan kuesioner kepada responden bertujuan untuk mengidentifikasi ketersediaan sumber air yang ada di lokasi penelitian, kemudian dilakukan pembobotan dengan menggunakan Skala Guttman. Skala pengukuran ini,

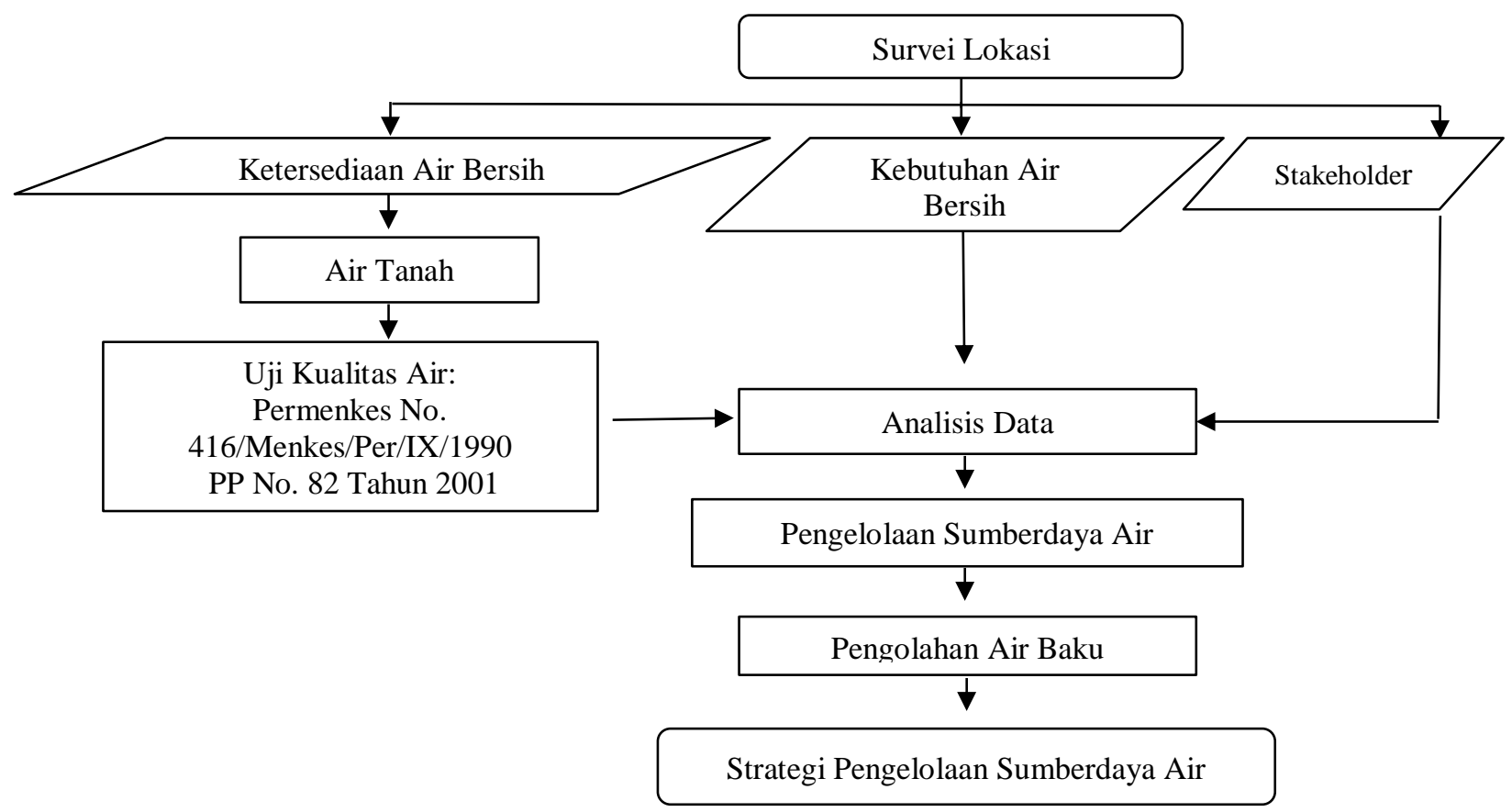

Gambar 1. Diagram alir tahapan penelitian

\begin{abstract}
c. Perhitungan Jumlah Kebutuhan Air dan Ketersediaan Air

Perhitungan jumlah kebutuhan air penduduk dilakukan dengan menggunakan kuesioner kepada responden. Bertujuan untuk mendapatkan informasi pemakaian air tiap individu, selanjutnya dilakukan analisis kebutuhan, dengan menggunakan rumus:
\end{abstract}

1). Rata-rata kebutuhan air individu (A)

$$
\mathrm{A}=\frac{\text { Total kebutuhan air per orang }}{\text { Banyaknya responden }}
$$

2). Jumlah kebutuhan air penduduk (B)

$\mathrm{B}=\mathrm{A} \times$ Jumlah penduduk

Dalam analisis ini diketahui jumlah kuantitas air/debit air baku yang tersedia kemudian dibandingkan dengan besarnya konsumsi air bersih penduduk. Analisis ini dimaksudkan untuk mengetahui seberapa besar kuantitas/kapasitas air yang dapat ditunjang untuk memenuhi kebutuhan air bersih penduduk dan sebagai penentu bagi pengelolaan sumberdaya air yang akan diterapkan di masyarakat. 


\section{d. Analisis Data}

Upaya untuk mengolah data atau menganalisa dari ke-2 (dua) data/ informasi tentang ketersediaan air bersih dan kebutuhan air bersih agar bermanfaat dalam pengambilan kesimpulan untuk kesejahteraan warga masyarakat Desa Harapan Jaya, Kecamatan Lasalimu Selatan.

\section{e. Analisis Kualitas Air}

Analisis kualitas air memberikan input data untuk pengelolaan maupun pengolahan air baku dan kepada pengambil keputusan untuk merancang strategi pengelolaan sumber air yang efektif. Sayogyanya pengelolaan maupun pengolahan air baku harus didukung oleh data kualitas air yang ada di lokasi penelitian. Uji kualitas air tersebut dilakukan di Laboratorium Depkes Provinsi Sulawesi Tenggara menggunakan standar Baku Mutu Air (BMA) berdasarkan Permenkes RI. No. 416/Menkes/Per/IX/1990 dan untuk pengkajian kelas air dan kriteria mutu air digunakan BMA PP. No. 82/2001.

Paramater kualitas air yang diamati adalah air baku berupa; air sumur yang umum digunakan oleh penduduk untuk memenuhi kebutuhan sehari-hari yaitu kekeruhan, kesadahan, sulfat, amonia, nitrit, besi, mangan, flourida, $\mathrm{pH}$, bau, rasa, warna, minyak, dan suhu. Sedangkan parameter kualitas air sungai yang diamati, antara lain: temperatur, TDS, TSS, pH, BOD, COD, $\mathrm{NO}_{3}$ sebagai $\mathrm{N}$, nitrit sebagai $\mathrm{N}$, total fosfat, $\mathrm{NH}_{3}-\mathrm{N}$, besi, kromium, cobalt, sulfat, mangan, Fecal Coliform, dan total Coliform.

\section{f. Analisis SWOT}

Untuk kebutuhan analisis data diambil dengan mengisi kuesioner terhadap para pakar/ stakeholder yang mengetahui tentang air bersih yang dipilih secara purposive sampling. Adapun tahapan dalam analisis SWOT, sebagai berikut: (1) Diawali dengan penentuan IFAS (Internal Faktor Analisis Strategi) dan EFAS (Eksternal Faktor Analisis Strategi) (Rangkuti, 2014), kemudian dikonversi kedalam bentuk matriks sehingga dapat ditentukan letak posisi dalam diagram SWOT (Kutarga, 2008); (2) Menyimpulkan dan merumuskan strategi yang tepat untuk mengantisipasi kelemahan dan ancaman, yang dijabarkan dalam strategis SWOT; (3) Mengimplementasikan strategi dalam operasional.

\section{Hasil dan Pembahasan}

\subsection{Ketersediaan Sumberdaya Air}

Hasil identifikasi potensi ketersediaan sumberdaya air di Desa Harapan Jaya berasal dari air sumur dan air Sungai Tokulo (Gambar 2) serta air hujan. Dalam keseharian masyarakat memanfaatkan air sumur sebagai sumber air bersih (Gambar 3) pada kedalaman 0-5 meter. Pada musim kemarau digunakan air sungai dan air sumur yang lebih dalam (Gambar 4). Untuk sumur yang mengandung minyak oleh masyarakat langsung dilakukan penutupan sehingga tidak bisa digunakan sebagai sumber air bersih.

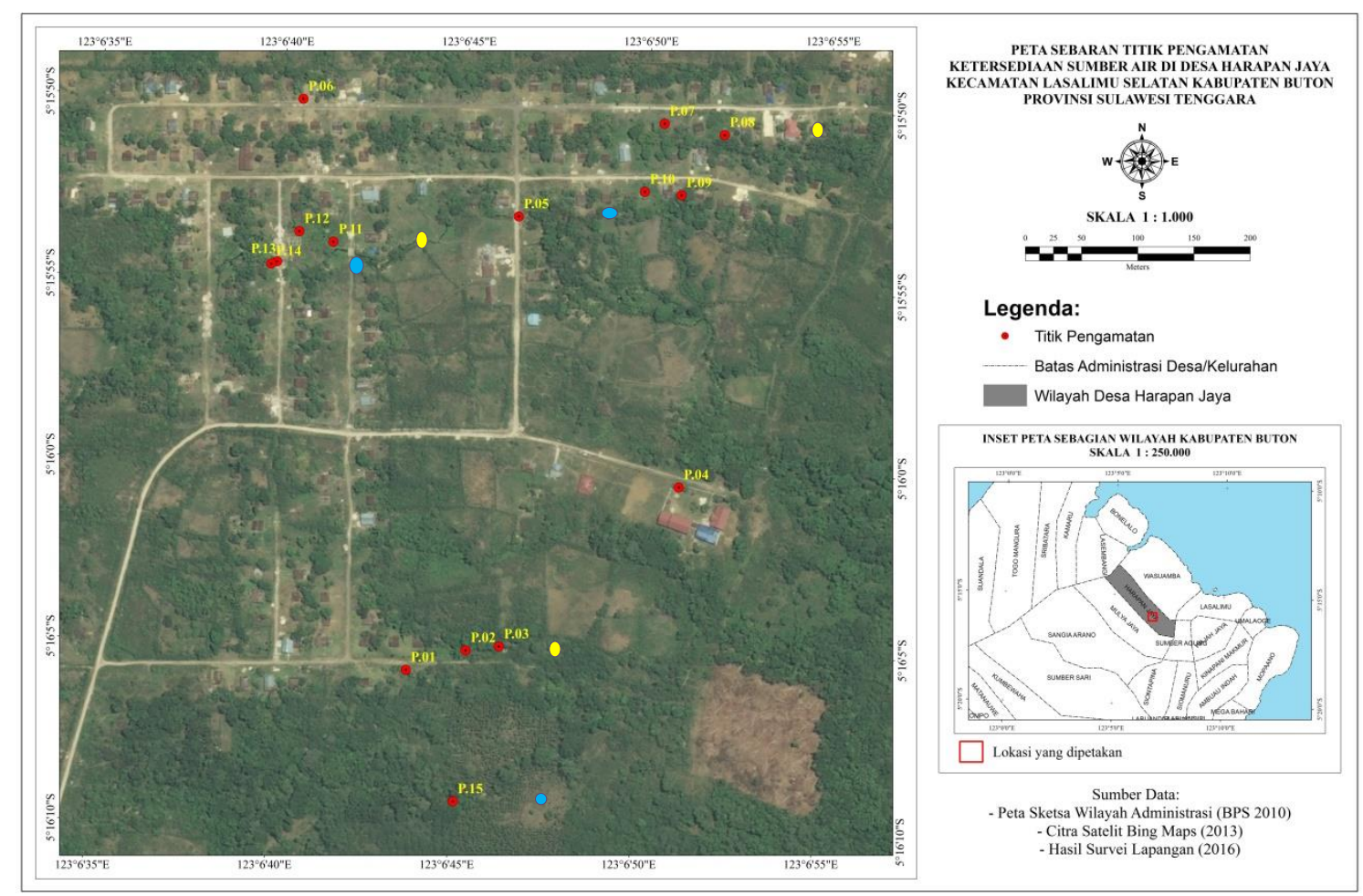

Gambar 2. Peta potensi ketersediaan sumberdaya air Desa Harapan Jaya 


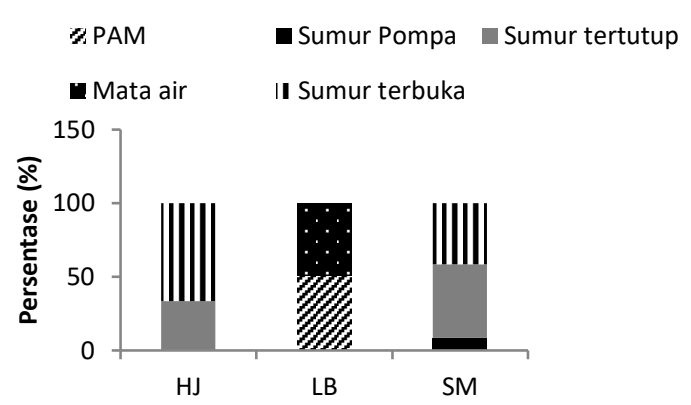

Gambar 3. Ketersediaan sumberdaya air di Desa Harapan Jaya (HJ), Laburunci (LB) dan Desa Sukamaju (SM).

\subsection{Kebutuhan Air Bersih Penduduk Desa Harapan Jaya}

Kebutuhan air bersih berdasarkan pemakaian tiap individu rata-rata sebesar $59 \mathrm{~L} /$ hari/orang dan kebutuhan air bersih seluruh penduduk Desa Harapan Jaya sebesar 42.893 L/hari; Desa Laburunci 151.440 L/hari; dan Desa Sukamaju 27.553 L/hari (Tabel 1), sementara BSN (2002) merekomendasikan standar kebutuhan air penduduk rata-rata per orang di daerah pedesaan adalah $60 \mathrm{~L} /$ hari/orang dan daerah perkotaan sebesar $120 \mathrm{~L} /$ hari/orang.

Hal ini menunjukkan bahwa tingkat pemakaian air bergantung pada aktivitas tiap individu, pola budaya dan status sosial. Kebutuhan air bersih di daerah perkotaan yang padat penduduknya lebih besar dibandingkan dengan daerah yang jarang/ sedikit penduduknya. Selain itu, jumlah anggota keluarga juga turut mempengaruhi penggunaan air bersih.

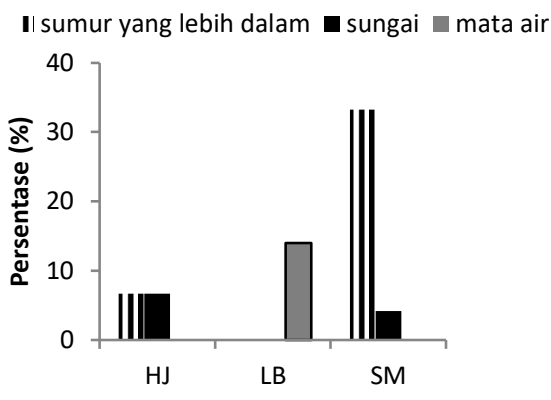

Gambar 4. Alternatif sumber air bersih di Desa Harapan Jaya (HJ), Desa Laburunci (LB) dan Desa Sukamaju (SM).

Tabel 1. Kebutuhan air bersih penduduk di Desa Harapan Jaya, Desa Laburunci dan Desa Sukamaju

\begin{tabular}{lccc}
\hline Lokasi & $\begin{array}{c}\text { Jumlah penduduk } \\
\text { (Orang) }\end{array}$ & $\begin{array}{c}\text { Kebutuhan air bersih } \\
\text { individu (L/hari/orang) }\end{array}$ & $\begin{array}{c}\text { Kebutuhan air bersih penduduk } \\
\text { (L/hari) }\end{array}$ \\
\hline Desa Laburunci & 2.524 & 60 & 151.440 \\
Desa Sukamaju & 467 & 59 & 27.553 \\
Desa Harapan Jaya & 727 & 59 & 42.893 \\
\hline
\end{tabular}

\subsection{Kualitas Air}

Kualitas air adalah kondisi mutu air yang diuji parameter-parameter tertentu dengan metode tertentu berdasarkan peraturan perundang-undangan yang berlaku. Saparuddin (2010) menyatakan bahwa disamping jumlah/volume air besar yang tidak kalah pentingnya adalah kualitas air yang memenuhi standar.

Pada penelitian ini, sampel air yang diuji kualitasnya adalah air bersih yang dipergunakan masyarakat dalam memenuhi kebutuhan sehariharinya. Untuk Desa Harapan Jaya dan Desa Sukamaju uji kualitas air bersihnya menggunakan sumber air yang berasal dari air sumur, sedangkan untuk Desa Laburunci menggunakan air bersih yang bersumber dari mata air. Uji kualitas air dilakukan penilaian sesuai dengan baku mutu yang berlaku di Indonesia. Penentuan terhadap keberadaan kualitas air
Penggunaan air bersih untuk keperluan sehari-hari hanya digunakan untuk keperluan seperti minum, masak dan MCK. Menurut Ariyanto dan Fahmi (2014), penggunaan air dari tempat yang satu dengan tempat yang lain berbeda disebabkan oleh faktor cuaca, lingkungan hidup, penduduk, industri dan faktor-faktor lainnya.

Sehubungan dengan pemakaian air bersih untuk kelangsungan hidup perlu mempertimbangkan jumlah pasokan air bersih yang tersedia (kuantitas air), karena bila kuantitas air bersih tersedia dalam jumlah yang melimpah maka kebutuhan akan air bersih dapat terpenuhi. Penggunaan air bersih untuk kebutuhan sehari-hari oleh masyarakat harus sesuai dengan potensi ketersediaan air/kuantitas air sehingga tidak terjadi krisis air bersih walaupun dalam kondisi kemarau panjang. 
2014); Kandungan amonia pada ketiga desa tersebut berada diatas ambang batas, sedangkan parameter lain, seperti: sulfat, nitrit, besi, flourida, bau, dan rasa berada pada kondisi aman dibawah baku mutu yang diperuntukkan. Kadar mangan pada Desa Harapan Jaya dan Desa Sukamaju tidak memenuhi standar, yaitu $0,50 \mathrm{mg} / \mathrm{L}$; sedangkan untuk derajat keasaman $(\mathrm{pH})$ air Desa Laburunci memiliki $\mathrm{pH}$ tertinggi dibandingkan dengan Desa Harapan Jaya dan Desa Sukamaju yaitu mencapai 7. Selanjutnya air yang berwarna ditemukan pada Desa Harapan Jaya, yaitu 20 TCU melampaui kadar maksimum, warna tersebut sangat berpengaruh terhadap kualitas air, menandakan terkandungnya partikel-partikel koloid dan kandungan zat lainnya (Sutapa, 2014). Dan air tersebut mengandung pula minyak sebanyak $0,20 \mathrm{mg} / \mathrm{L}$ bila dibiarkan terus menerus akan terakumulasi dalam tubuh manusia dan mempengaruhi kesehatan. Penduduk setempat menjelaskan hal itu terjadi karena adanya pengaruh kondisi morfologi tanah dan batuan, sedangkan pengukuran temperatur air yang harus dipenuhi berkisar $+3{ }^{\circ} \mathrm{C}$ dari suhu udara. Berdasarkan PP. RI No. 82/2001 sumber air yang terdapat pada ketiga desa tersebut tergolong air kelas II.

Menurut Pramudya et al. (2010) bila terdapat minimum satu parameter fisik-kimia yang nilai minimum, rata-rata, dan nilai maksimum telah melampaui baku mutu air sesuai peruntukkannya, maka air tersebut dapat dikatakan tercemar berat.

Tabel 2. Kualitas air baku di Desa Harapan Jaya, Desa Laburunci dan Desa Sukamaju

\begin{tabular}{|c|c|c|c|c|c|}
\hline \multirow[b]{2}{*}{ Parameter } & \multirow[b]{2}{*}{ Satuan } & \multicolumn{3}{|c|}{ Hasil Uji Laboratorium } & \multirow[b]{2}{*}{ Baku mutu } \\
\hline & & $\begin{array}{c}\text { Desa } \\
\text { Harapan Jaya } \\
\text { (Air sumur) }\end{array}$ & $\begin{array}{c}\text { Desa } \\
\text { Sukamaju } \\
\text { (Air sumur) }\end{array}$ & $\begin{array}{c}\text { Desa } \\
\text { Laburunci } \\
\text { (Mata air) }\end{array}$ & \\
\hline Kekeruhan & NTU & 0,1 & 6,6 & 40,3 & 25 \\
\hline Kesadahan & $\mathrm{mg} / \mathrm{L}$ & 302 & 727 & 377 & 500 \\
\hline Sulfat & $\mathrm{mg} / \mathrm{L}$ & 95 & 105 & 92 & 400 \\
\hline Amonia & $\mathrm{mg} / \mathrm{L}$ & 1,20 & 1,15 & 2,01 & 0,0 \\
\hline Nitrit & $\mathrm{mg} / \mathrm{L}$ & 0,02 & 0,05 & 0,07 & 1 \\
\hline Besi & $\mathrm{mg} / \mathrm{L}$ & 0,01 & 0,03 & 0,02 & 1,0 \\
\hline Mangan & $\mathrm{mg} / \mathrm{L}$ & 0.5 & 0,5 & 0,4 & 0,4 \\
\hline Flourida & $\mathrm{mg} / \mathrm{L}$ & $<0,02$ & 0,17 & $<0,02$ & 1,5 \\
\hline $\mathrm{pH}$ & - & 6,4 & 6,8 & 7,0 & $6,5-9,0$ \\
\hline $\mathrm{Bau}$ & - & Normal & Normal & Normal & Tidak berbau \\
\hline Rasa & - & Normal & Normal & Normal & Tidak berasa \\
\hline Warna & TCU & 20 & Tidak terdeteksi & Tidak terdeteksi & 50 \\
\hline Minyak & $\mathrm{mg} / \mathrm{L}$ & 0,20 & Tidak terdeteksi & Tidak terdeteksi & - \\
\hline Suhu & ${ }^{\circ} \mathrm{C}$ & 28 & 26 & 24 & +3 \\
\hline
\end{tabular}

Permenkes No. 416/Menkes/Per/IX/1990

\subsection{Pengelolaan Sumberdaya Air Desa Harapan Jaya}

Berdasarkan hasil survei data debit air/kuantitas air, baik itu air tanah (air sumur) maupun air sungai sangat sulit karena belum ada sistem pendataan yang dilakukan sehingga sumber air baku yang dijadikan penentuan kuantitas air pada penelitian ini adalah air hujan. Hasil penentuan kuantitas air yang tersedia di daerah ini dengan menggunakan data curah hujan dari data (BPS, 2014) yaitu $3681 \mathrm{~mm} /$ tahun menghasilkan debit air hujan sebesar $9.20 \times 10^{6} \mathrm{~m}^{3} /$ tahun.

Jika diasumsikan membangun embung pada lahan seluas setengah hektar dari areal Desa Harapan Jaya, maka air hujan yang dapat ditampung sebesar 18.405 $\mathrm{m}^{3} /$ tahun. Jumlah tersebut bila dibandingkan dengan jumlah kebutuhan air bersih penduduk mampu untuk memenuhi jumlah konsumsi air bersih penduduk di Desa Harapan Jaya (727 jiwa) sebesar 15.655,95 $\mathrm{m}^{3} /$ tahun. Secara teoritis cara ini dapat memecahkan masalah pemenuhan kebutuhan air bagi Desa Harapan Jaya teratasi dengan memanfaatkan potensi air hujan.

Terkait pengelolaan sumberdaya air mempertimbangkan kondisi geografis daerah, tingkat pendapatan masyarakat, curah hujan, ketersediaan sumber air, kualitas air baku (air sumur dan air sungai) dan kebutuhan akan air bersih, maka pengelolaan sumberdaya air yang tepat adalah dengan membangun embung (Abdurrachman et al., 2008; Maarif, 2011; Widiyono, 2011).

Menurut Sazakali et al. (2007) air hujan merupakan sumber potensial air minum, begitu pula di Kota Istanbul (Basak dan Alagha, 2004). Panen air hujan selain dapat digunakan untuk pertanian tadah hujan/pasokan air, juga untuk rumah tangga (Helmreich dan Hom, 2009). Dalam memenuhi kebutuhan air, sistem pemanenan air hujan sangat efektif (Li et al., 2000) dan menawarkan potensi besar sebagai pasokan air alternatif (Lee et al., 2010). Khumar et al. (2005) menerangkan bahwa di India pembangunan berkelanjutan dan pengelolaan air menyoroti pada air hujan, karena dianggap sebagai entry point untuk tata kelola air tawar (Carpenter et al., 1998).

Untuk mengelola sumberdaya air di daerah pedesaan seperti Desa Harapan Jaya dibutuhkan teknik pengelolaan yang berbasis masyarakat, terpadu dan berkelanjutan sehingga dapat menyelesaikan kendala yang dialami oleh desa tersebut. Keterlibatan masyarakat sangat diharapkan sebagai pendorong keandalan sistem penyediaan air bersih, yang pada akhirnya menaikkan tingkat kepuasan masyarakat. Pengelolaan air bersih selain didukung oleh partisipasi masyarakat juga sangat penting harus didukung oleh 
keterlibatan stakeholder dalam manajemen pengelolaan sumberdaya (Path-Wostl et al., 2007).

\subsection{Proses Pengolahan Air Baku}

Hasil evaluasi uji kualitas air diatas menggambarkan kondisi air baik air sumur maupun air sungai berada pada golongan air kelas II. Oleh karena itu, perlu adanya dilakukan pengolahan air sebelum air tersebut digunakan oleh masyarakat.

Setiap areal atau wilayah memiliki pengolahan air sendiri-sendiri sesuai dengan kondisi geologi dan kebutuhan. Untuk mengolah air bersih secara optimal di daerah pedesaan adalah membuat suatu inovasi pengolahan air bersih yang sederhana, murah serta ramah lingkungan. Teknologi pengolahannya harus didasarkan pada kemampuan lokal, bahan dan peralatan, serta kondisi keterbatasan ekonomi masyarakat. Salah satu pengolahan air bersih yang sangat mudah adalah pengolahan air hujan karena memiliki kelebihan, relatif masih bersih dibandingkan dengan sumber air baku lainnya. Proses pengolahan air hujan menjadi air bersih dapat dilakukan dengan beberapa tahap, yaitu: (1) Sistem penampungan (embung) ini merupakan bangunan yang dibangun dan berfungsi sebagai pemanen air hujan. Tujuannya adalah untuk penyediaan air di musim kemarau. Biasanya dibuat permanen atau semi permanen (Subagyono et al., 2004). Proses penampungan air, sebaiknya berada di dataran yang lebih tinggi dari pemukiman penduduk (Widiyono, 2011); (2) Filtrasi diperlukan untuk menghindari pencemaran oleh bakteri dan bahan kimia berbahaya. Air hujan yang ditampung dimasukan ke dalam tangki untuk proses filtrasi. Hal tersebut diatas dilakukan untuk menyaring kotoran dan partikel-partikel tersuspensi; (3) Untuk mendistribusikan air kepada penduduk dilakukan dengan menggunakan metode gravitasi (Nelwan et al., 2013), sehingga untuk distribusi penyaluran air ke penduduk akan lebih efektif dan efisien dalam penggunaan biaya. Teknik terakhir adalah pemberian kapur untuk penetralisir kadar asam dari air hujan dan desinfeksi sebelum distribusi penyaluran agar pasokan air bersih kepada penduduk tetap aman.

\subsection{Strategi Pengelolaan Sumberdaya Air}

Berdasarkan hasil analisis SWOT pada analisis faktor internal dan faktor eksternal, diperoleh data skor total dari masing-masing faktor-faktor, sebagai berikut: skor total kekuatan $=0,95$; skor total kelemahan $=2,05$; skor total peluang $=2,26$; skor total ancaman $=0,85$. Hasil tersebut kemudian dimaknai ke dalam diagram SWOT, sebagaimana yang disajikan dalam Gambar 5.

Dari identifikasi faktor internal dan eksternal, memiliki peluang yang besar untuk mengatasi ancaman maupun kelemahan yang ada, terutama dukungan pemerintah merupakan peluang utama, artinya dukungan pemerintah sangat kuat pengaruhnya dalam pengelolaan air bersih yang akan direncanakan pelaksanaannya. Berdasarkan hasil identifikasi kedua faktor tersebut diatas maka dapat diperoleh kesimpulan dalam strategi pengelolaan air bersih yang dapat diimplementasikan.

Tampak Gambar 5 menunjukkan letak posisi diagram SWOT strategi pengelolaan air bersih yang berada di Desa Harapan Jaya berada pada posisi kuadran 3, titik koordinatnya yaitu titik $(-1.1,1.4)$. Posisi kuadran tersebut merupakan posisi staretegi dengan menghadapi peluang yang sangat besar tetapi menghadapi beberapa kendala atau kelemahan internal. Upaya lain yang dapat dilakukan adalah meminimalkan masalah-masalah internal sehingga dapat merebut peluang atau dengan cara memanfaatkan seluruh peluang yang ada untuk meminimalisir segala kelemahan-kelemahan yang ada dalam pengelolaan sumberdaya air bersih di Desa Harapan Jaya.

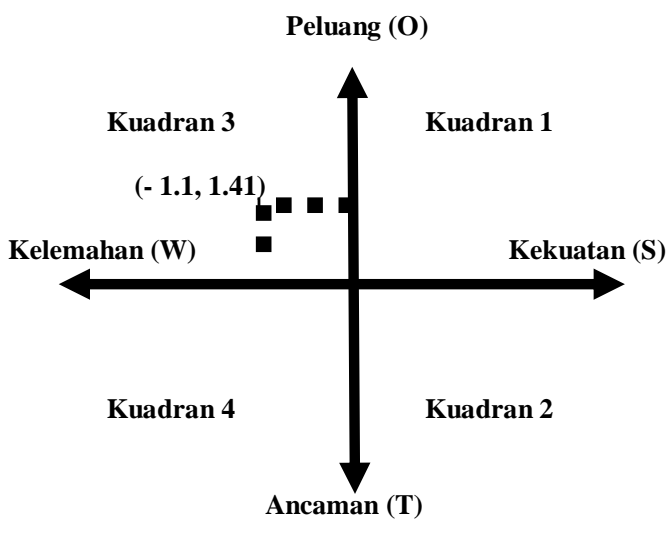

\section{Gambar 5. Diagram SWOT strategi pengelolaan air bersih}

Setelah diperoleh hasil analisis di agram SWOT di atas, didapatkan matriks SWOT yang digunakan untuk menggambarkan bagaimana strategi pengelolaan air bersih yang akan dilakukan. Strategi yang akan digunakan adalah strategi WO, sebagaimana disajikan pada matriks SWOT Tabel 3.

\section{Kesimpulan}

Dari hasil penelitian yang telah dilakukan, dapat disimpulkan beberapa hal sebagai berikut:

1. Ketersediaan sumberdaya air di lokasi transmigrasi Desa Harapan Jaya Kec. Lasalimu Selatan dalam rangka memenuhi kebutuhan air bersih sehari-hari berupa adalah air tanah (air sumur galian), air permukaan (Sungai Tokulo) dan air hujan.

2. Kebutuhan air bersih di Desa Harapan Jaya adalah sebesar 59 L/hari/orang, sehingga kebutuhan air bersih seluruh penduduk di Desa Harapan Jaya Kec. Lasalimu Selatan adalah $15.656 \mathrm{~m}^{3} /$ tahun. 
Tabel 3. Matriks analisis SWOT strategi W-O pengelolaan sumberdaya air bersih Desa Harapan Jaya

\begin{tabular}{|c|c|}
\hline IFAS & $\begin{array}{l}\text { WEAKNESSES }(\mathrm{W}) \\
\text { 1. Ketidak-tersediaan tenaga ahli } \\
\text { 2. Training/pelatihan untuk mengolah air baku } \\
\text { 3. Kualitas air bersih } \\
\text { 4. Kondisi perekonomian masyarakat } \\
\text { 5. Sistem pengalokasian dana desa } \\
\text { 6. Sarana dan prasarana yang mendukung air bersih } \\
\text { 7. Penguasaan teknologi }\end{array}$ \\
\hline $\begin{array}{ll}\text { 1. } & \text { Dukungan pemerintah } \\
\text { 2. } & \text { Pelaksanaan sistem perundang- } \\
\text { undangan sumberdaya air } \\
\text { 3. } \\
\text { Pelaksanaan perlindungan hukum } \\
\text { terhadap sumberdaya air } \\
\text { 4. } \\
\text { Budaya masyarakat menggunakan air } \\
\text { 5. Persih } \\
\text { 6. } \\
\text { 7. } \\
\text { Kerjasama dengan puntuan masyarakat }\end{array}$ & $\begin{array}{l}\text { 1. Dukungan pemerintah untuk mendatangkan tenaga } \\
\text { ahli dan mengadakan training untuk mengolah air } \\
\text { baku sesuai perkembangan teknologi kepada } \\
\text { masyarakat desa. } \\
\text { 2. Implementasi UU yang mendukung pengelolaan } \\
\text { dan pengolahan sumberdaya air agar dapat } \\
\text { menjamin kualitas sumberdaya air. } \\
\text { 3. Pemerintah memberikan bantuan dana karena } \\
\text { kondisi perekonomian masyarakat yang minim } \\
\text { untuk pengadaan sarana dan prasarana air bersih } \\
\text { desa agar terpenuhi tuntutan masyarakat. } \\
\text { 4. Mengadakan kerjasama dengan pihak swasta dalam } \\
\text { penguasaan teknologi dan bantuan dana untuk biaya } \\
\text { pengolahan maupun pengadaan sarana-prasarana air } \\
\text { bersih. } \\
\text { 5. Sosialisasi budaya menggunakan air bersih serta } \\
\text { pemeliharaan sarana dan prasarana air bersih. }\end{array}$ \\
\hline
\end{tabular}

3. Untuk mendukung terpenuhinya kebutuhan air bersih di daerah tersebut perlu dilakukan pengelolaan bersumber dari air hujan, yang berpotensi memasok sebesar $3.681 \mathrm{~mm} / \mathrm{tahun}$ atau sekitar $18.405 \mathrm{~m}^{3} /$ tahun.

4. Proses pengolahan air bersih yang dianjurkan yaitu dengan cara sederhana, murah dan ramah lingkungan. Proses pengolahannya yaitu dengan metode sistem penampungan embung, sistem filtrasi dan distribusi dengan sistem gravitasi.

5. Implementasi strategi pengelolaan air bersih adalah strategi peluang dalam meminimalisir kelemahan strategi W-O (WeaknessesOpurtunities), dengan prioritas utama meminta dukungan pemerintah terkait kapasitas dan kapabilitasnya dalam pengelolaan sumberdaya air (termasuk air hujan).

\section{Daftar Pustaka}

[1] [BPS] Badan Pusat Statistik, 2014. Kabupaten dalam Angka 2014. Pasarwajo, BPS Kab. Buton.

[2] [BSN] Badan Standarisasi Nasional, 2002. Penyusunan Neraca Sumberdaya Air Spasial. SNI No. 19-6728.1-2002, Jakarta.

[3] [UNICEF] Unite for Children, 2012. Ringkasan Kajian: Air Bersih, Sanitasi dan Kebersihan. Unicef Indonesia, Indonesia.

[4] Amalia B.I., A. Sugiri, 2014. Ketersediaan Air Bersih dan Perubahan Iklim: Studi krisis Air di Kedungkarang Kabupaten Demak. Jurnal Teknik PWK. 3(2), pp. 295-302.

[5] Anuar K., A. Ahmad, Sukendi, 2015. Analisis Kualitas Air Hujan Sebagai Sumber Air Minum terhadap Kesehatan Masyarakat (Studi Kasus di Kecamatan Bangko Bagansiapiapi). Jurnal Dinamika Lingkungan Indonesia. 2(1), pp. 32-39.
[6] Ariyanto A., K. K. Fahmi, 2014. Prediksi Jumlah Kebutuhan Air Bersih BPAB Unit Dalu-Dalu 5 Tahun mendatang (2018) Kecamatan Tambusai Kabupaten Rakun Hulu. Teknik Sipil Universitas Pesir Pengairan. ejournal. 1(1).

[7] Bakti H, W. Naily, R. F. Lubis, R. M. Delinom, Sudaryanto, 2014. Penjejak Keluaran Air Tanah Lepas Pantai (KALP) di Pantai Utara Semarang dan Sekitarnya dengan 222Radon. Jurnal Riset Geologi dan Pertambangan. 24(1), pp. 43-51.

[8] Basak B., O. Alagha, 2004. The Chemical Composition of Rainwater Over Büyükçekmece Lake, Istanbul. Atmospheric Research. 71(4), pp. 275-288.

[9] Carpenter S.R., N. F. Caraco, D. L. Correll, R. W. Howarth, A. N. Sharpley, V. H. Smith, 1998. Nonpoint Pollution of Surface Waters with Phosphorus and Nitrogen. Ecology applications. 8(3), pp. 559-568.

[10] Helmreich B., B. Hom, 2009. Opportunities in Rainwater Harvesting. Desalination. 248(1), pp. 118-124.

[11] Herlambang A., N. I. Said, 2005. Aplikasi Teknologi Pengolahan Air Sederhana untuk Masyarakat Pedesaan. JAI BPPT. 1(2), pp. 113-122.

[12] Herlambang A., 2006. Pencemaran Air dan Strategi Penanggulangannya. JAI BPPT. 2(1), pp. 16-29.

[13] Khumar R, R. D. Singh, K. D. Sharma, 2005. Water Resources of India. CURRENT SCIENCE. 89(5), pp. 794811.

[14] Kutarga Z. W., 2008. Kajian Penataan Ruang Kawasan Danau Laut Tawar dalam Rangka Pengembangan Wilayah Kabupaten Aceh Tengah [tesis]. Universitas Sumatera Utara, Medan.

[15] Lee J. Y., Yang J. S., Han M., Choi J., 2010. Comparison of The Microbiological and Chemical Characterization of Harvested Rainwater and Reservoir Water as Alternative Water Resources. Science of the Total Enviroment. 408(4), pp. 896-905.

[16] Li Fengrui, S. Cook, T. Gordon, Geballe, R. William. Jr. Burch, 2000. Rainwater Harvesting Agriculture: An Integrated System for Water Management on Rainfed Land in China's Semiarid Areas. Journal of the Human Environment. 29(8), pp. 477-483. 
[17] Lubis Z, N. A. Affandy, 2014. Kebutuhan Air Bersih di Kecamatan Glagah Kabupaten Lamongan. Jurnal Teknika. 6(2), pp. 577-584.

[18] Maarif S. 2011. Meningkatkan Kapasitas Masyarakat dalam Mengatasi Risiko Bencana Kekeringan. Jurnal Sains dan Teknologi Indonesia. 13(2): 65-73.

[19] Muliranti S, M. P. Hadi, 2013. Kajian Ketersediaan Air Meteorologis untuk Pemenuhan Kebutuhan Air Domestik di Provinsi Jawa Tengah dan DIY. Jurnal Bumi Indonesia. 2(2).

[20] Nelwan F, E. M. Wuisan, L. Tanudjaja, 2013. Perencanaan Jaringan Air Bersih Desa Kima Bajo Kecamatan Wori. Jurnal Sipil Statik. 1(10), pp. 678-684.

[21] Path-Wostl C. P., M. Craps, A. Dewulf, E. Mostert, D. Tabara, T., 2007. Social Learning and Water Resources Management. Ecology dan society. 12(2).

[22] Pemerintah Republik Indonesia. 2001. Peraturan Pemerintah No. 82 Tahun 2001 tentang Pengelolaan Kualitas Air dan Pengendalian Pencemaran Air. Sekretariat Negara.

[23] Pramudya B, I. Djuwita, E. Riani, 2010. Penentuan Status Mutu Air Kali Surabaya dengan Metode Storet dan Indeks Pencemaran.

[24] Rangkuti F, 2014. Analisis SWOT Teknik Membedah Kasus Bisnis. PT. Gramedia Utama Jakarta, Jakarta.

[25] Saparuddin, 2010. Pemanfaatan Air Tanah Dangkal Sebagai Sumber Air Bersih di Kampus Bumi Bahari Palu. Jurnal SMARTek. 8(2), pp. 143-152.
[26] Sazakali E., A. Alexopoulos, M. Leotsinidis, 2007. Rainwater Harvesting, Quality Assessment and Utilization in Kefalonia Island, Greece. Water research. 41(9), pp. 20392047.

[27] Setyaningsih W. 2010. Model Pergerakan Bahan Pencemar Minyak Disel pada Akuifer Batupasir Formasi Volkanik Merapi Muda. Jurnal Geografi. 7(2):75-87.

[28] Subagyono, Kasdi, U. Haryati, S. H. Talaohu, 2004. Teknologi Konservasi Air pada Pertanian Lahan

Kering. Dalam: Kurnia U, Rachman A, Dariah A (Eds.). Teknologi Konservasi Tanah pada Lahan Kering Berlereng. Puslitbang Tanah dan Agroklimat, Badan Litbangtan, pp. 151-188.

[29] Sudiran, Anrianisa, Fi. 2016. Efektifitas Instalasi Pengolahan Air (IPA) Unit 2 Tirta Kencana Pdam Kota Samarinda Terhadap Kualitas Air Minum Tahun 2015. Dedikasi. 34(1), pp. 59-76.

[30] Sutapa I. D. A., 2014. Perbandingan Efisiensi Koagulasi Poli Aluminium Khlorida dan Aluminium Sulfat dalam Menurunkan Turbiditas Air Gambut dari Kabupaten Katingan Provinsi Kalimantan Tengah. Jurnal Riset Geologi dan Pertambangan. 24(1), pp. 13-21.

[31] Widiyono W. 2011. Konservasi Flora, Tanah dan Sumberdaya Air Embung-Embung di Timor Barat Provinsi Nusa Tenggara Timur (Studi Kasus Embung Oemasi-Kupang dan Embung Leosama-Belu). Jurnal Teknologi Lingkungan. 9(2). 